\title{
Propriedades físico-químicas, sensoriais e bacteriológicas de camarões (Litopenaeus brasiliensis) irradiados e armazenados sob refrigeração
}

\section{Physical, chemical, sensorial and bacterial properties of irradiated shrimp (Litopenaeus brasiliensis) stored under refrigeration}

\author{
Marcelo Sireno, ${ }^{*}$ Eliane Teixeira Mársico, ${ }^{* *}$ Micheli da Silva Ferreira, ${ }^{* *}$ Maria Lúcia Guerra Monteiro, ${ }^{\text {** }}$ \\ Hélio de Carvalho Vital, ${ }^{* * *}$ Carlos Adam Conte Junior, ${ }^{* *}$ Sérgio Borges Mano**
}

\begin{abstract}
Resumo
A irradiação de alimentos é uma opção tecnológica para minimizar problemas de perdas de alimentos, pois reduz as alterações provenientes da atividade bacteriana, estendendo a validade do produto. Neste estudo foram irradiados camarões (Litopenaeus brasiliensis) com doses de 1,5 e 2,5 kGy, após 30 dias de armazenamento sob refrigeração $\left(2^{\circ} \mathrm{C} \pm 2^{\circ} \mathrm{C}\right)$, com o objetivo de avaliar os efeitos da irradiação sobre a validade comercial de camarões através de parâmetros físico-químicos, microbiológicos e sensoriais. Foram avaliados pH, bases voláteis totais (BVT), contagem de bactérias heterotróficas aeróbias mesófilas (BHAM) e heterotróficas aeróbias psicrófilas (BHAP) e teste de aceitação sensorial. Os valores de $\mathrm{pH}$ não variaram entre as amostras controle e as amostras irradiadas apresentando média de 7,08 $\pm 0,21$ durante os 30 dias de armazenamento. A produção de BVT nas amostras controle extrapolou o limite aceitável para o consumo no 15o dia de armazenamento enquanto nas amostras irradiadas com 2,5 kGy, este limite não foi alcançado em 28 dias de armazenamento, demonstrando o efeito positivo da utilização da irradiação. Na análise sensorial, não ocorreu diferença significativa ( $p>0,01)$ na aceitação, quanto aos atributos de sabor, aparência, aroma e impressão global entre as amostras.
\end{abstract}

Palavras-chave: radiação gama, camarão, validade comercial, análises físico-químicas, análises sensoriais, análises bacteriológicas.

\begin{abstract}
Food irradiation is currently regarded as a technological option to mitigate food losses due to its potential in reducing microbiological load and its associated spoilage effects, consequently extending the shelf life of many products. Samples of shrimp (Litopenaeus brasiliensis) have been exposed to gamma doses of $0,1.5$ and $2.5 \mathrm{kGy}$ and monitored changes in sensorial characteristics (30 judges), $\mathrm{pH}$ and total volatile bases (TVB) levels. All samples were kept at $2^{\circ} \mathrm{C} \pm 2{ }^{\circ} \mathrm{C}$ through the experiments. No significant change in $\mathrm{pH}$ has been observed during the experiments regardless of the gamma dose applied. There was statistical difference between the non-irradiated samples and those irradiated with $2.5 \mathrm{kGy}(\mathrm{p}<0.01)$, though no significant difference has been found between the non-irradiated samples and those irradiated with $1.5 \mathrm{kGy}$ nor between the samples irradiated with $1.5 \mathrm{kGy}$ and those irradiated with $2.5 \mathrm{kGy}$. Based on the upper commercial limit for NB, non-irradiated samples achieved the limit in 15 days while the samples irradiated with $2.5 \mathrm{kGy}$ didn't achieve the limit in 28 days. In sensorial analyses, there was no significant difference $(p>0.01)$ in the acceptance, according to the attributes flavor, appearance, aroma and global impression among the samples.
\end{abstract}

Keywords: shrimp, gamma irradiation, shelf life, physical and chemical analyses, sensorial analysis, bacterial analysis.

\section{Introdução}

Como todos os produtos pesqueiros, o camarão é altamente susceptível à deterioração, fator agravado pela possibilidade de oxidação de certas substâncias do tipo amino-fenol, frequentemente oriundas do desdobramento de proteínas pela ação bacteriana, provocando a melanose ou "blackspot", pela formação de melanina. Dentre os métodos de conservação disponíveis para prolongar a validade comercial de alimentos, a irradiação merece destaque, diminuindo riscos à saúde pública através da redução do crescimento microbiano e de processos químicos responsáveis pela

\footnotetext{
*Programa de Pós-graduação em Irradiação de Alimentos da Faculdade de Veterinária da Universidade Federal Fluminense - Rua Vital Brazil Filho, 64. Niterói, RJ, CEP 24230-340.

**Programa de Pós-graduação em Higiene Veterinária e Processamento Tecnológico de Produtos de Origem Animal da Faculdade de Veterinária da Universidade Federal Fluminense;

***Instituto de Pesquisa e Desenvolvimento - Centro Tecnológico do Exército

A quem enviar a correspondência: Eliane Teixeira Mársico - e-mail: elianee@vm.uff.br
} 
degradação precoce do alimento. Além de ser um eficiente método de conservação, a irradiação também é responsável por reduzir a alergenicidade do camarão, especificamente da tropomiosina (Byun et al., 2002).

Em geral, durante o processo de irradiação ocorrem pequenas alterações químicas: podem ser formados produtos radiolíticos como a glicose, o ácido fórmico, o aldeído acético e o dióxido de carbono, os quais também são encontrados naturalmente em alimentos submetidos aos tratamentos térmicos convencionais (GCIIA, 1991).

O objetivo deste estudo foi avaliar os efeitos da irradiação gama sobre os parâmetros físico-químicos, a validade comercial de camarões mantidos em refrigeração $\left(2^{\circ} \mathrm{C} \pm\right.$ $2^{\circ} \mathrm{C}$ ) e sua aceitação pelo consumidor. A estabilidade das amostras irradiadas e não irradiadas foi monitorada, durante o armazenamento, através da mensuração de pH e produção de BVT, além do acompanhamento do desenvolvimento de BHAM e BHAP. O grau de aceitação do produto foi observado através de análise sensorial.

\section{Material e métodos}

As amostras utilizadas foram da espécie L. brasiliensis, obtidas no mercado de peixes da Barra da Tijuca - RJ. Após obtenção, os exemplares foram subdivididos em três lotes de aproximadamente $500 \mathrm{~g}$ cada, destinados aos três diferentes tratamentos (G0 - grupo controle: não submetido à irradiação, G1 - grupo 1: irradiado com 1,5 kGy e G2 - grupo 2: irradiado com 2,5 kGy). As amostras foram pesadas, descabeçadas e lavadas, visando diminuir a contaminação inicial, colocadas em sacos plásticos e identificadas por etiquetas, acondicionadas em recipiente isotérmico com gelo e imediatamente transportadas para o IPD/CTEX.

$\mathrm{Na}$ irradiação das amostras, utilizou-se o irradiador de pesquisa do Instituto de Pesquisa e Desenvolvimento (IPD), localizado no Centro Tecnológico do Exército (CTEX) em Guaratiba, Rio de Janeiro, RJ. A atividade atual de sua fonte de $137 \mathrm{CS}$ é de $51 \mathrm{kCi}$, gerando uma taxa de dose máxima de aproximadamente 2,0 kGy/h.

Durante o processo de irradiação, as amostras foram acondicionadas em embalagens plásticas e posteriormente acondicionadas em recipiente isotérmico com gelo. O tempo de irradiação foi de uma hora para o tratamento com 1,5 kGy e de uma hora e 40 minutos para a dose de 2,5 kGy, com a temperatura média no interior do irradiador em tomo de $33^{\circ} \mathrm{C}$. Todas as amostras foram colocadas novamente em recipiente isotérmico com gelo e encaminhadas para os laboratórios da Faculdade de Veterinária da Universidade Federal Fluminense, onde foram armazenadas sob refrigeração a $2^{\circ} \mathrm{C} \pm 2^{\circ} \mathrm{C}$ durante 30 dias. Durante este período, foram realizadas as análises de determinação de $\mathrm{pH}$ e de BVT, a contagem de BHAM e BHAP, e o teste de aceitação sensorial.

Para determinação de $\mathrm{pH}$ foi utilizado o método potenciométrico, e para a análise de BVT, o método de Microdifusão de Conway (Brasil, 1981). A contagem de bactérias heterotróficas aeróbicas mesófilas (CBHAM) e bactérias heterotróficas aeróbicas psicrófilas (CBHAP) foram procedidas segundo Morton (2001).
Para a análise sensorial, as amostras foram retiradas da geladeira, descascadas, pesadas, lavadas, temperadas com $1 \%$ de $\mathrm{NaCl}$, fritas em panela antiaderente acrescidas de duas colheres de sopa de óleo de soja, em fogo médio sob temperatura em torno de $120^{\circ} \mathrm{C}$. Após sete minutos, os camarões foram retirados e secos em guardanapos de papel. Para a degustação, as amostras mantiveram-se aquecidas em banho-maria a $50^{\circ} \mathrm{C}$, sendo servidas em copos descartáveis individuais codificados com números randômicos de três dígitos, e apresentadas aos julgadores de forma sequencial, de modo que cada julgador provou todas as amostras em ordem de apresentação aleatória.

Alguns exemplares de cada grupo foram previamente separados para testes de aroma e aparência. Para a análise do aroma, as amostras cruas e com casca foram colocadas em béqueres identificados (no total de três), dispostos sob placa aquecida a $45^{\circ} \mathrm{C}$. Para a análise de aparência, as amostras foram dispostas em pratos de plástico com fundo branco, identificados com os mesmos números e colocados sob luz natural. Os testes foram realizados sob condições laboratoriais com 30 consumidores não treinados. Foi empregada uma escala hedônica estruturada de nove pontos para os atributos de sabor, aparência, aroma e impressão global (Stone e Siedel, 1993).

\section{Análise Estatística}

Os índices de aceitação dos consumidores foram tratados estatisticamente usando-se o programa computacional SAS (1999) a partir da análise de variância (ANOVA) e teste de Turkey. Para os resultados relativos às análises de $\mathrm{pH}$ e BVT, foram utilizados a estatística descritiva e o teste de regressão linear, com o mesmo programa computacional.

\section{Resultados e discussão}

Não foi observada diferença significativa dos valores de $\mathrm{pH}$ entre as amostras controle e as amostras irradiadas com 1,5 e 2,5 kGy, sendo observada a média de 7,1 $\pm 0,2$ para os três grupos. O valor mínimo obtido para os três grupos foi de 6,8 e o máximo foi de 7,3 .

A avaliação do pH tem fundamental importância, pois os valores se elevam em função da produção de compostos nitrogenados voláteis decorrentes da decomposição química e microbiológica no pescado. Quando o pH alcança aproximadamente 7,6, o camarão se torna inaceitável para o consumo, embora o limite máximo estabelecido pelo RIISPOA seja de 6,5 a 6,8 (BRASIL, 2008). Esse fato foi verificado por Shamshad et al. (1990), que observaram valores inicial e final relativamente mais altos que neste estudo, com variação entre 7,1 e 8,3 após 16 dias de armazenamento a $0^{\circ} \mathrm{C}$. Mendes et al. (2005) consideraram camarões (Parapenaeus longirostris) com pH igual ou inferior a 7,9 como aceitáveis para o consumidor quando correlacionaram atributos sensoriais.

Outros autores evidenciaram aumentos de $\mathrm{pH}$ maiores no grupo controle quando comparado com o grupo de amostras irradiadas. Em estudo com camarão da Malásia (Macrobrachium rosenbergii), Leitão e Rios (2000) observaram variação de $\mathrm{pH}$ entre 7,7 e 8,4 nas amostras estocadas a $0^{\circ} \mathrm{C}$ e a $5^{\circ} \mathrm{C}$ respectivamente, não sendo 
constatada diferença entre as temperaturas de armazenamento. Mayer (2000), estudando este parâmetro na mesma espécie, também evidenciou valores mais altos nas amostras controle $(7,5$ a 8,3) após 14 dias de armazenamento sob refrigeração $\left(5^{\circ} \mathrm{C}\right)$.

Com relação à pesquisa de BVT, as amostras não irradiadas (controle) desse estudo apresentaram um aumento gradual que variou de $12,09 \mathrm{mgN} / 100 \mathrm{~g}$, no 1 ㅇ dia, a $36 \mathrm{mgN} / 100 \mathrm{~g}$ no 15 dia de armazenamento, quando as amostras foram consideradas impróprias para consumo por ultrapassar o limite oficial de $30 \mathrm{mgN} / 100 \mathrm{~g}$ para este parâmetro (BRASIL, 2008). Para as amostras irradiadas com $1,5 \mathrm{kGy}$ os valores variaram entre $10,08 \mathrm{mgN} / 100 \mathrm{~g}$, no 1 o dia e $28,5 \mathrm{mgN} / 100 \mathrm{~g}$ no $22^{\circ}$ dia, aumentando em 7 dias a validade comercial, e $34,14 \mathrm{mgN} / 100 \mathrm{~g}$ no 25 dia de armazenamento. As amostras irradiadas com 2,5 kGy obtiveram valores variando entre 6,61 $\mathrm{mgN} / 100 \mathrm{~g}$, no 1으 dia, e 21,47 mgN/100g no $27^{\circ}$ dia de armazenamento sob as mesmas condições, não alcançando durante o experimento o valor máximo preconizado pela legislação.

De acordo com Ogawa et al. (1999), para pescado em excelente estado de frescor, o teor de BVT varia entre 5 a $10 \mathrm{mgN} /$ $100 \mathrm{~g}$ de carne; em peixes com frescor razoável podem atingir de 15 a $25 \mathrm{mgN} / 100 \mathrm{~g}$. No início da deterioração, este teor pode alcançar de 30 a $40 \mathrm{mgN} / 100 \mathrm{~g}$ e, quando mais avançado, este teor encontra-se acima de $50 \mathrm{mgN} / 100 \mathrm{~g}$. No presente estudo, segundo a classificação do autor supracitado, os camarões irradiados com 2,5 kGy, no fim do armazenamento (27dias), apresentaram frescor razoável, enquanto as amostras não irradiadas e irradiadas com 1,5 kGy apresentaram perfil de BVT compatível com início de putrefação.

Os valores de BVT em função dos dias de armazenamento podem ser observados na Figura 1. A regressão linear foi significativa ao nível de $5 \%$ de probabilidade para os três grupos estudados, cujos valores de $\mathrm{R}^{2}$ oscilaram entre 0,88 e 0,71 , caracterizando um bom ajuste das equações, demonstrando o efeito positivo combinado da utilização da irradiação com uso do frio, que determinou uma redução no processo de deterioração, triplicando a vida útil do produto.

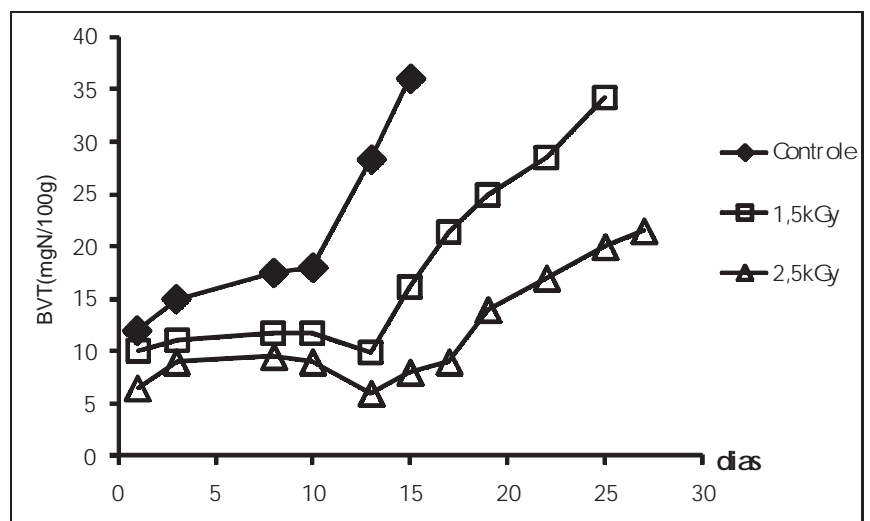

Figura 1: Valores de BVT (Bases voláteis totais) em $\mathrm{mgN} / 100 \mathrm{~g}$ em amostras de camarão não irradiados (controle) e irradiados com 1,5 e $2,5 \mathrm{kGy}$ e mantidos sob refrigeração $\left(2^{\circ} \mathrm{C} \pm 2^{\circ} \mathrm{C}\right)$.

Shamshad et al. (1990) relatam que alterações no teor de BVT são dependentes do tempo e da temperatura de arma- zenamento. Os autores evidenciaram teor de 21,4 mgN/l00g em amostras estocadas por 12 dias sob temperatura de $0^{\circ} \mathrm{C}$ e, 20,2 mgN/l00g em somente 5 dias de armazena-mento a $10^{\circ} \mathrm{C}$, demonstrando a importância da temperatura no controle da qualidade deste produto. Este resultado é respaldado pelo fato de que o aumento de temperatura acelera a taxa de crescimento bacteriano, acelerando o processo de deterioração e indicando que a atividade microbiana pode ser um fator significativo para alteração do produto. Lacroix et al. (1995) estudando o efeito da radiação gama na qualidade de camarões (Penaeus monodon) também evidenciaram uma extensão no prazo de vida comercial deste produto.

Segundo Leitão e Rios (2000) a produção de BVT é mais intensa sob temperatura de armazenamento de $5^{\circ} \mathrm{C}$ e, extremamente reduzida a $0^{\circ} \mathrm{C}$. Segundo estes autores, o valor máximo permitido pela legislação brasileira é alcançado em apenas cinco dias de armazenamento sob temperatura de $5^{\circ} \mathrm{C}$ e, em temperatura de $0^{\circ} \mathrm{C}$, este valor não é alcançado em dez dias.

Özden et al. (2007) obtiveram valores crescentes de BVT em amostras de pargo (Pagrus pagrus), com variação entre 15,65 $\mathrm{mgN} / 100 \mathrm{~g}$ no início do armazenamento a 38,64 mgN/100g para as amostras controle e $13,48 \mathrm{mgN} / 100 \mathrm{~g}$ para as amostras irradiadas a 2,5 kGy após 19 dias.

O presente estudo evidenciou uma diminuição da produção de BVT com uso da irradiação, o que está de acordo com o objetivo do processo, que é redução da microbiota no camarão, uma vez que, nos produtos marinhos a formação de TMA a partir da TMAO no músculo dos peixes é atribuída à ação de bactérias ou enzimas encontradas nos cecos pilóricos dos mesmos originando, como produtos finais, aminas (Araújo et al., 1975; Morga, 1975). Estes autores descrevem a E. coli, e as bactérias do gênero Staphylococcus, Klebsiella e Proteus como as principais bactérias redutoras do OTMA.

Considerando a avaliação sensorial, os resultados podem ser observados na Tabela 1, que apresenta os escores de aceitação com relação aos atributos sabor, aparência, aroma e impressão global em amostras de camarão não irradiados e irradiados com 1,5 e 2,5 kGy. Observa-se que não ocorreu diferença significativa quanto aos atributos avaliados, entre os grupos de amostras estudados, o que demonstra ser favorável a utilização de irradiação gama no produto estudado.

Tabela 1: Escores de aceitação sensorial dos atributos sabor, aparência, aroma e impressão global em amostras de camarão não irradiados e irradiados com 1,5 e 2,5 kGy

\begin{tabular}{cccccc}
\hline Tratamento & $\mathbf{n}$ & Sabor & Aparência & Aroma & $\begin{array}{c}\text { Impressão } \\
\text { global }\end{array}$ \\
\hline Controle & 30 & $8,03^{\mathrm{a}}$ & $7,63^{\mathrm{a}}$ & $7,23^{\mathrm{a}}$ & $7,90^{\mathrm{a}}$ \\
$1,5 \mathrm{kGy}$ & 30 & $7,86^{\mathrm{a}}$ & $7,30^{\mathrm{a}}$ & $7,06^{\mathrm{a}}$ & $7,66^{\mathrm{a}}$ \\
$2,5 \mathrm{kGy}$ & 30 & $7,76^{\mathrm{a}}$ & $7,00^{\mathrm{a}}$ & $6,66^{\mathrm{a}}$ & $7,63^{\mathrm{a}}$
\end{tabular}

Médias na mesma coluna seguidas com a mesma letra indicam diferença não significativa ao nível de $1 \%$ de significância $(p>0,01)$. 
Lacroix et al. (1995), estudando amostras de camarão précozido submetido à radiação gama, concluíram que este processo não altera a aceitabilidade do produto, o que está de acordo com os resultados do presente estudo. Na análise sensorial de outras espécies de peixes, Siqueira (2000) verificou a textura mais íntegra em tilápia irradiada em até 20 dias de armazenamento sob refrigeração; quanto ao pescado não irradiado, foram observadas alterações marcantes na textura como desintegração fácil das fibras e presença de muco em grande quantidade. Lopez (2006) verificou que o processo de irradiação não influenciou nos parâmetros de aparência, aroma e sabor em amostras de camarão branco do pacífico, e que a aceitabilidade quanto a aparência e aroma decresceu ao longo do período de armazenamento de 21 dias, tanto para as amostras controle como para as irradiadas a 1 e 3,5 kGy. Com relação ao sabor, os provadores declararam gostar de ligeiramente a muitíssimo das amostras controle e irradiadas, levando o autor a concluir que as doses usadas não interferiram no sabor.
A inativação de patógenos através da irradiação também foi estudada por Lopes (2006) em camarão-branco do pacífico (Litopenaeus vannamei). Neste estudo foi observada uma diminuição da população de Staphylococcus sp. (em até 0,4 log UFC/g), coliformes totais (em até 1,7 NMP/g) e termotolerantes (em até $0,3 \mathrm{NMP} / \mathrm{g}$ ), psicrotrófilos (em até 3,5 log UFC/g) e mesófilos (em até 2,2 log UFC/g), evidenciando que a irradiação reduziu a população bacteriana e, durante todo o período de armazenamento de 21 dias, as amostras irradiadas continuaram a atender os padrões previstos pela legislação. Contudo, as amostras não irradiadas, após uma semana de armazenamento, estavam impróprias para o consumo por extrapolarem o limite para Staphylococcus sp.

Lopes (2006) observou uma tendência de queda da população de Staphylococcus sp. nas amostras irradiadas a 1 e 3,5 kGy, que manteve-se até o 14ㅇ dia de armazenamento, enquanto as amostras não irradiadas foram descartadas no 7으 dia de estocagem.

Com relação às contagens de $\mathrm{BHAM}$ e $\mathrm{BHAP}$, os resultados obtidos podem ser visualizados nas Figuras 2 e 3 .
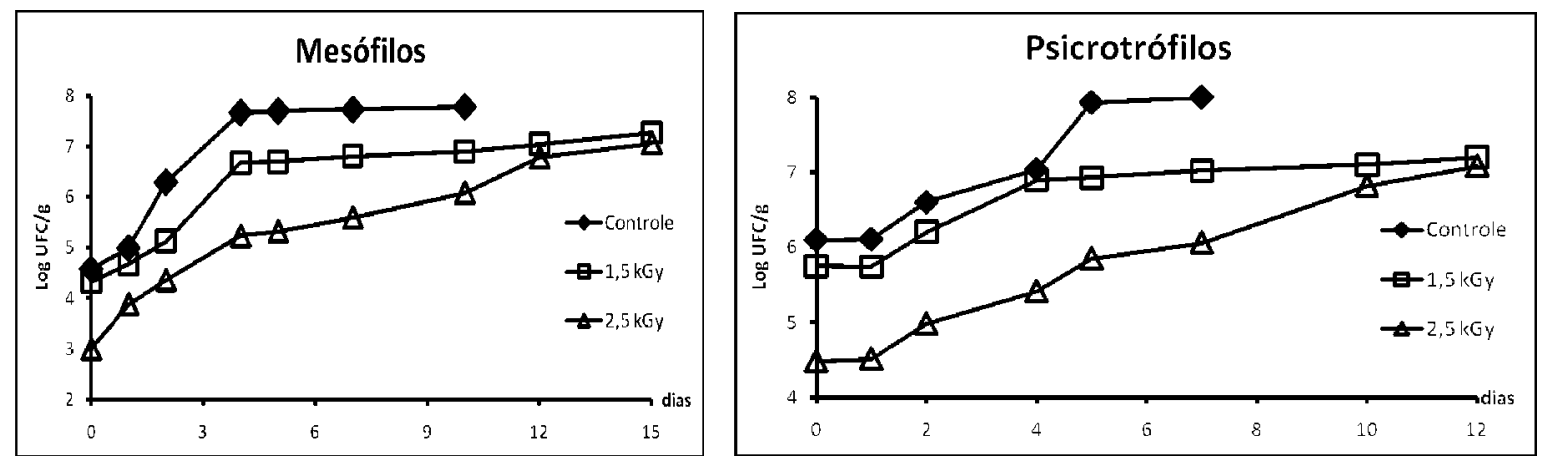

Figura 2a e b: Valores das Contagens de Bactérias Heterotróficas Aeróbias Mesófilas e Bactérias Heterotróficas Aeróbias Psicrófilas nas amostras de camarão não irradiada (controle), irradiada com 1,5kGy e irradiada com 2,5kGy

Conforme os resultados demonstrados, a contagem bacteriana aumentou nas amostras controle assim como nas amostras irradiadas no decorrer da estocagem, tanto para BHAM como para BHAP. A evolução da cinética bacteriana nas amostras irradiadas foi inversamente proporcional à dosagem de irradiação efetuada, demons-trando a eficácia da irradiação na diminuição de micro-organismos no alimento estudado.

Tais resultados estão de acordo com diversos estudos, como o de Mayer (2000) que irradiou amostras de camarão-rosa (Penaeus brasiliensis e Penaeus paulensis) com doses de 1 e 3,5 kGy. O autor obteve uma redução da população de microorganismos psicrotrófilos e mesófilos em cinco ciclos logarítmicos, além de reduzir a população inicial de Pseudomonas spp., prolongando a validade comercial do camarão em até 21 dias sob refrigeração $\left(5^{\circ} \mathrm{C}\right)$.

Foley et al. (2005) obtiveram resultados de redução da população inicial de Listeria monocitogenes inoculada em salada de frutos do mar armazenada a $4^{\circ} \mathrm{C}$ em 2,6 e $4 \mathrm{log}$ UFC com irradiação de 0,7 kGy, quantidade menor de irradiação que a usada no presente estudo.

\section{Conclusões}

De acordo com os resultados obtidos, o processo de irradiação gama com doses de 1,5 e 2,5 kGy demonstrou ser eficiente na conservação de camarões (L. brasiliensis) mantidos sob refrigeração, tanto no aspecto de qualidade físico-química e microbiológica quanto sensorialmente.

Além de evidenciar a eficiência na conservação, a irradiação gama aumentou o prazo de validade comercial de camarões irradiados com 1,5 kGy em oito dias e, em 14 dias as amostras submetidas a 2,5 kGy, demonstrando mais um aspecto favorável na utilização desta tecnologia para a indústria de camarões.

A irradiação gama, nas doses de 1,5 e 2,5 kGy, não causou diferenças significativas nos atributos sensoriais sabor, aroma, aparência e impressão global, o que atribuiu à irradiação ser um processo bastante positivo, pois quando se utiliza alguma nova tecnologia para conservação de alimentos, deve-se sempre considerar as características sensoriais do produto de modo a não interferir ou interferir positivamente no seu consumo. 
Os resultados observados neste estudo fortalecem a utilização da irradiação gama como método de conservação eficaz para camarões. Não obstante, outros trabalhos devem

\section{Referências}

ARAÚJO, A.A.; VIEIRA, G.H.F.; VIEIRA, R.D.S.;TELLES, F.J.S. Redução do óxido de Trimetilamina por Bactérias. Arquivos de Ciências do Mar, v. 15, n. 2, p. 101-103, 1975.

BRASIL. Ministério da Agricultura. Departamento Nacional de Inspeção de Produtos de Origem Animal. Regulamento da Inspeção Industrial e Sanitária de Produtos de Origem Animal - RIISPOA. Aprovado pelo Decreto ํo 30.691, de 29/03/52, alterado pelo Decreto no 1255 de 25/ 06/62. Brasília, DF, 1997.

BRASIL. Ministério da Agricultura. Secretaria Nacional de Defesa Agropecuária. Laboratório Nacional de Referência Animal. Métodos Oficiais para Controle de Produtos de Origem Animal e seus Ingredientes II - Métodos Físicos e Químicos. Brasília, DF, 1981.

BYUN, M.; LEE, J.; YOOK, H.; JO, C.; KIM, H. Application of gamma irradiation for inhibition of food allergy. Radiat Phys Chem, v. 63, p. 369-370, 2002.

FOLEY, D.M.; TRIMBOLI, S.L.; LAMB, J.; GOGLEY, J.; THOMPSON, J.; CAPORASO, F.; CALICCHIA, M.; PRAKASH, A. Acid-adaptation does not increase the resistance of Listeria monocytogenes to irradiation in a seafood salad. Int J Food Microbiol., v. 99, n. 2, p. 147-56, 2005. GCIIA. GRUPO CONSULTIVO INTERNACIONALSOBRE IRRADIAÇÃO DE ALIMENTOS - GCIIA. A irradiação de alimentos: ficção e realidade. Ficha Descritiva 1-14. 1991.

LACROIX, M.L.; JOBIN, M.; LATREILLE, B.; NOUCHPRAMOOL, K.; GAGNON, M. The effect of gamma irradiation on physical and nutritional quality of Penaeus monodon shrimps. Radiation Phys.Chem, Oxford, v. 46, n. 4-6, p. 731-737, 1995.

LEITÃO, M.F.F.; RIOS, D.P.A. Microbiological and chemical changes in freshwater prawn (Macrobrnchium rosembergii) stored under refligeration. Braz. J. Microbiol., v. 31, n. 3, 2000.

LOPES, T.G.G. Efeito sinergístico da radiação gama e da refrigeração na conservação do camarão brando do pacífico (Litopenaeus vannamei). 2006. 95 f. Dissertação (Mestrado em Ciência e Tecnologia de Alimentos). Universidade de São Paulo. Escola Superior de Agricultura "Luiz de Queiroz". Piracicaba, 2006. Disponível em: <www.teses.usp.br/teses/disponiveis/11/11141/tde-30082006143457/pt-br.php>. Acesso em: 2010. utilizar diferentes doses de irradiação e temperaturas de armazenagem visando otimizar o efeito combinado dessas técnicas para aplicação na indústria de camarões.

MAYER, A. Alterações microbiológicas, fisico-químicas e sensoriais durante a vida útil do camarão rosa (Litopenaeus brasiliensis e Litopenaeus paulensis) submetido à radiação gama. Disponível em:<www.cena.usp.br/irradiação/teses.htm.2000>. Acesso em: 2009.

MENDES, R.; GONÇALVES, A.; PESTANA, J.; PESTANA, C. Índole production and deepwater pink shrimp (Parapenaeus longirostris) decomposition. European Food Research and Technology, Berlin, v. 221, p. 329-335, 2005.

MORGA, A. Avaliação do índice de frescor da Pescada Foguete, Macrodon ancylodon, conservada em gelo. 1975. 80 f. Dissertação (Mestrado em Ciências dos Alimentos) - Universidade Estadual de Campinas, Campinas,1975. Disponível em: <www.mpu.furg.br/ cd2010/cic/227.doc>. Acesso em: 2010.

MORTON, R. D.; Aerobic Plate Cout. In: SOWENS, F. P., ITO, K. Compendium of Methods for the Microbiological Contamination of Foods, 4 ed. American Public Health Association (APHA). Washington, 2001, 670 p., cap. 7, p. 63-67.

OGAWA, M.; MAIA, E. I. Manual de pesca: ciência e tecnologia do pescado. São Paulo: Varela, 1999, v. 1, 430 p.

ÖZDEN, O.; INUGUR, M; ERKAN, N. Preservation of iced refrigerated sea bream (Sparus aurata) by irradiation: microbiological, chemical and sensory attributes. Eur Food Res Technol, v. 225, p. 797-805, 2007.

SHAMSHAD, S.I.; KHER-UM-NISA.; RIAZ, M.;ZUBERI, R.; QADRI, R.D. Shelf life of Shrimps (Penaeus merguiensis) stored at different temperatures. Journal of Food Science, Chicago, v. 55, p. 12011205, 1990.

SIQUEIRA, A.A.Z.; Efeitos da Irradiação e Refrigeração na Qualidade e no Valor Nutritivo da Tilápia (Oreochromis niloticus). 2001.137 f. Dissertação (Mestrado em Ciência e Tecnologia de Alimentos). Universidade de São Paulo. Escola Superior de Agricultura "Luiz de Queiroz". Piracicaba, 2001. Disponível em: <www.teses.usp.br/ teses/disponiveis/11/11141/tde-15032002-151922/pt-br.php>. Acesso em: 2010.

STONE, H.; SIEDEL, J.L. Sensory Evaluation Practices. 2. ed. California: Academic Press, 1993. 338 p. 